\title{
KASP: a genotyping method to rapid identification of resistance in Plasmodium falciparum
}

\author{
Ana Alvarez-Fernandez ${ }^{1}$, María J. Bernal ${ }^{1}$, Isabel Fradejas², Alexandra Martin Ramírez ${ }^{1}$, Noor Azian Md Yusuf ${ }^{3}$,
} Marta Lanza', Shamilah Hisam³ ${ }^{3}$ Ana Pérez de Ayala² and José M. Rubio ${ }^{1^{*}}$ (D)

\begin{abstract}
Background: The emergence and spread of anti-malarial resistance continues to hinder malaria control. Plasmodium falciparum, the species that causes most human malaria cases and most deaths, has shown resistance to almost all known anti-malarials. This anti-malarial resistance arises from the development and subsequent expansion of Single Nucleotide Polymorphisms (SNPs) in specific parasite genes. A quick and cheap tool for the detection of drug resistance can be crucial and very useful for use in hospitals and in malaria control programmes. It has been demonstrated in different contexts that genotyping by Kompetitive Allele Specific PCR (KASP), is a simple, fast and economical method that allows a high-precision biallelic characterization of SNPs, hence its possible utility in the study of resistance in P. falciparum.

Methods: Three SNPs involved in most cases of resistance to the most widespread anti-malarial treatments have been analysed by PCR plus sequencing and by KASP (C580Y of the Kelch13 gene, Y86N of the Pfmdr1 gene and M133I of the Pfcytb gene). A total of 113 P. falciparum positive samples and 24 negative samples, previously analysed by PCR and sequencing, were selected for this assay. Likewise, the samples were genotyped for the MSP-1 and MSP-2 genes, and the Multiplicity of Infection (MOI) and parasitaemia were measured to observe their possible influence on the KASP method.
\end{abstract}

Results: The KASP results showed the same expected mutations and wild type genotypes as the reference method, with few exceptions that correlated with very low parasitaemia samples. In addition, two cases of heterozygotes that had not been detected by sequencing were found. No correlation was found between the $\mathrm{MOI}$ or parasitaemia and the KASP values of the sample. The reproducibility of the technique shows no oscillations between repetitions in any of the three SNPs analysed.

Conclusions: The KASP assays developed in this study were efficient and versatile for the determination of the Plasmodium genotypes related to resistance. The method is simple, fast, reproducible with low cost in personnel, material and equipment and scalable, being able to core KASP arrays, including numerous SNPs, to complete the main pattern of mutations associated to $P$. falciparum resistance.

Keywords: Plasmodium falciparum, KASP, Resistance, SNPs, K13, MDR, Cytb

*Correspondence: jmrubio@isciii.es

${ }^{1}$ Malaria \& Parasitic Emerging Diseases Laboratory, National Microbiology Center, Instituto de Salud Carlos III, Madrid, Spain

Full list of author information is available at the end of the article

\section{Background}

Malaria remains an important problem in global public health, being a mayor cause of morbidity and mortality that continues to claim more than 400,000 lives every

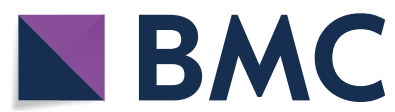

(c) The Author(s) 2021. This article is licensed under a Creative Commons Attribution 4.0 International License, which permits use, sharing, adaptation, distribution and reproduction in any medium or format, as long as you give appropriate credit to the original author(s) and the source, provide a link to the Creative Commons licence, and indicate if changes were made. The images or other third party material in this article are included in the article's Creative Commons licence, unless indicated otherwise in a credit line to the material. If material is not included in the article's Creative Commons licence and your intended use is not permitted by statutory regulation or exceeds the permitted use, you will need to obtain permission directly from the copyright holder. To view a copy of this licence, visit http://creativeco mmons.org/licenses/by/4.0/. The Creative Commons Public Domain Dedication waiver (http://creativecommons.org/publicdomain/ zero/1.0/) applies to the data made available in this article, unless otherwise stated in a credit line to the data. 
year [1]. The continuing devastating impact of this disease is partly due to the emergence and spread of resistance to anti-malarials [2].

Plasmodium parasites quickly develop resistance to anti-malarials and evade the immune system through mutations in their genome. Since an effective vaccine has not yet been developed, control and surveillance of antimalarial resistance is crucial for saving lives [3]. Plasmodium falciparum, the species that causes most human malaria cases and most deaths, has shown resistance to almost all known anti-malarials [4]. In fact, recently, cases of delayed parasite clearance following treatment with an artemisinin-based combination therapy (ACT) have been reported in the Greater Mekong sub-region. This represent a major threat to the ability to control and treat malaria, since this is the current first line treatment for uncomplicated $P$. falciparum infections $[3,5]$. This anti-malarial resistance arises from the development and subsequent expansion of Single Nucleotide Polymorphisms (SNPs) in specific parasite genes [6, 7]. To identify and monitor the propagation of these resistances, SNPs can be detected by molecular analysis. The usual method of resistance detection is the Polymerase Chain Reaction (PCR) and sequencing or digested with restriction enzymes [7]. Moreover, next generation sequencing genotyping is an emerging method of genotyping SNPs that is increasingly being adopted for both diagnosis and research [8].

Despite these advances, rapid, simple, affordable method that can be transferred to the daily clinic are necessary to detect possible resistance in the patient and to a fast population screening of resistance at low cost. It has been demonstrated that genotyping by Kompetitive Allele Specific PCR (KASP), is a simple, fast and economical method that allows a high-precision biallelic characterization of SNPs, as well as insertions and deletions in specific loci, hence its possible utility in the study of resistance in $P$. falciparum.

The KASP method introduces fluorescence resonance energy transfer (FRET) for signal generation, where two fluorescent cassettes are used for the identification of allele-specific amplification for a single biallelic SNP [9]. The process begins with the first round of the PCR, where one of the allele-specific primers matches the target SNP and, with the common reverse primer, amplifies the target region. The common reverse primer also binds and PCR proceeds, with the allele specific primer becoming incorporated into the template. During this phase, the fluor-labelled oligos remain bound to their quencher-labelled complementary oligos, and no fluorescent signal is generated. As PCR proceeds further, one of the fluor-labelled oligos, corresponding to the amplified allele, is also incorporated into the template, and is hence no longer bound to its quencher-labelled complement. As the fluor is no longer quenched, the appropriate fluorescent signal is generated (Fig. 1) [6].

This method has been used, for example, for the detection of SNPs associated with the efficacy of specific drugs [9]; for genotyping candidate genes associated with the development of genetic diseases, such as Huntington's disease [10]; or for the genotyping of SNPs associated with G6PD deficiency [11].

Given the importance of rapid response for guidance in the administration of anti-malarial treatment in certain patients, a quick and cheap tool, as KASP, for the detection of drug resistance can be crucial and very helpful for use in hospitals and malaria control programmes. The objective of this study is to verify the possible utility of the KASP technique in the analysis of resistance to anti-malarial drugs. To validate the method, three SNPs involved in most of the resistance of the most widespread treatments have been selected: i) SNP C580Y of the gene that codes for the Kelch13 protein (Gene PF3D7_1343700) that is present in 80\% of cases of resistance to artemisinin treatments [12]; ii) SNP Y86N of the Pfmdr1 gene (gene PF3D7_0523000) that is involved in resistance to different drugs such as quinine, chloroquine, mefloquine, halofantrine, amodiaquine and lumefantrine; the latter frequently used in combination with artemisinin, and where a natural selection of this SNP has been observed after treatment [13-15]; and iii) SNP M133I of the Pfcytb gene (gene MAL MYTH 3) that is related to resistance to atovaquone [16] and menoctone [17], being the most frequent mutation in vitro tests.

\section{Methods}

\section{Sample collection}

The $P$. falciparum resistance genotype of those patients who presented a single malaria infection was analyzed as part of a prospective, observational, multicentre study, approved by the Medical and Health Research Ethics Committee (CEIC) of the Hospital Universitario 12 de Octubre (CEIm: 18/021).

The final selection was based on species-specific identification by nested-PCR $[18,19]$ and only samples with unique infection with $P$. falciparum were chosen for the study.

A total of 112 P. falciparum positive samples and 24 negative samples were selected for this assay. In addition, a strain, donated by the Parasitology Department of the Institute for Medical Research in Malaysia with 


\section{Assay components:}

A) KASP Assay Mix: consists of 2 allele specific primers and 1 reverse primer.

B) KASP Master Mix: contains universal fluorescent probes, Taq polymerase and dNTP's in an optimised buffer solution.

C) Sample DNA: DNA contains the SNP of interest.

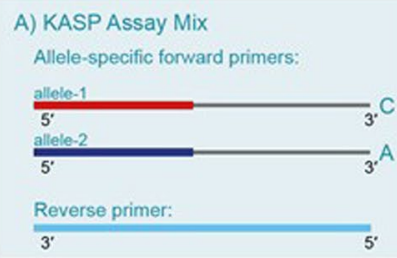

B) KASP Master Mix

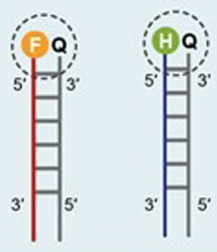

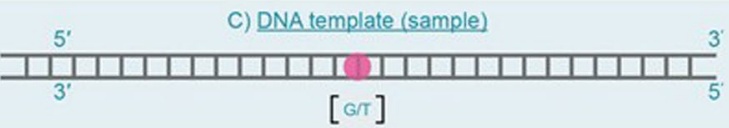

\section{Denatured template and annealing} components - PCR round 1:

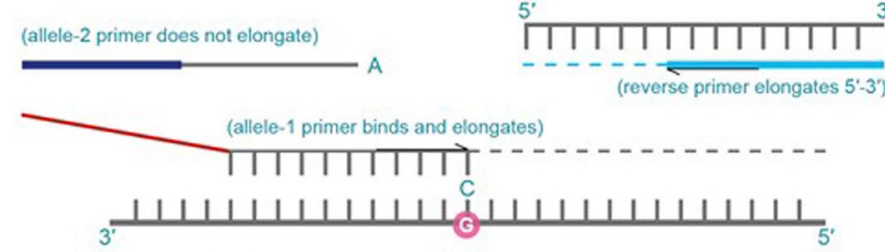

In the first round of PCR, one of the allele-specific primers matches the target SNP and with the common reverse primer, amplifies the target region.

\section{Complement of allele-specific tail sequence generated - PCR round 2:}

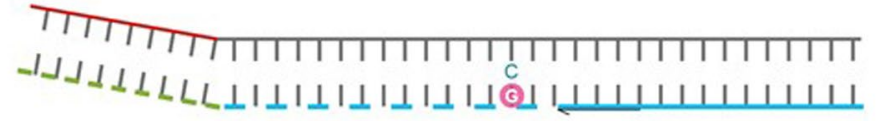

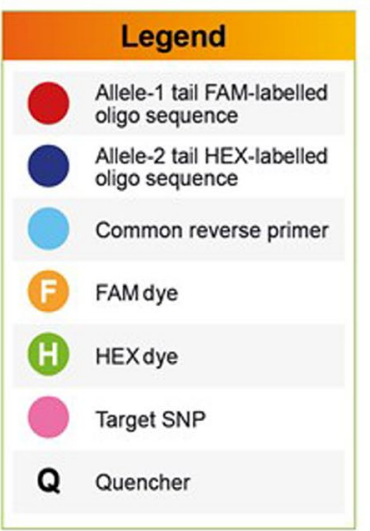

(Reverse primer binds, elongates and makes a complementary copy of the allele-1 tail.)

\section{Signal generation - PCR round 3 :}

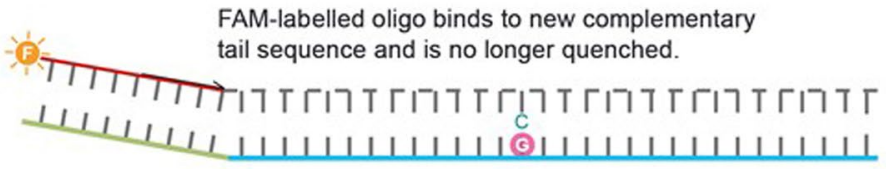

In further rounds of PCR, levels of allele- specific tail increase. The fluor labelled part of the FRET cassette is complementary to new tail sequences and binds, releasing the fluor from the quencher to generate a fluorescent signal.

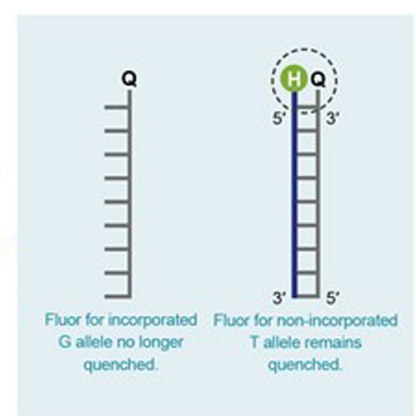

Fig. 1 A schematic approach to the KASP mechanism of action

the mutation C580Y of the gene that codes for the Kelch13 protein, was included.

\section{Sample processing}

DNA was extracted from $200 \mu \mathrm{l}$ of whole blood, collected in ethylenediamine tetraacetic acid (EDTA) tubes, using the QIAamp DNA mini blood kit (QIAGEN ${ }^{\circledR}$, Hilden, Germany) according to the manufacturer's instructions, resuspended in a final volume of $100 \mu \mathrm{l}$ of distilled water. The DNA is stored at $4{ }^{\circ} \mathrm{C}$ until use, using $5 \mu \mathrm{l}$ per reaction.

\section{Plasmodium falciparum resistance genotyping}

Genotyping of Pfmdr1, Pfcytb and PfK13 genes was carried by real time PCR modified from the original methods [20-22]. Reaction mixture consists of $1 \times$ QUANTIMIX HotSplit Probes kit (Biotools, Madrid, Spain) $0.25 \mu \mathrm{M}$ of each primer (Table 1 ) and $1 \mu \mathrm{M}$ EvaGreen ${ }^{\circledR}$ dye (Biotium, 
Table 1 Primers name, gene target, sequence and method for the $P$. falciparum resistance genotyping

\begin{tabular}{|c|c|c|c|}
\hline Target & Primer name/reference & Method & Seq. $5^{\prime} \rightarrow 3^{\prime}$ \\
\hline \multirow[t]{8}{*}{ MDR } & MDR1-pfmdr1-1FK76T' & RT-PCR MDR A and sequencing & GTTGAACAAAAAGAGTACCGCTG \\
\hline & MDR2-pfmdr1-1RK76T ${ }^{21}$ & & TCGTACCAATTCCTGAACTCAC \\
\hline & MDR3-pfmdr1-2FK76T 21 & Sequencing & TTTCCGTTTAAATGTTTACCTGC \\
\hline & MDR4-pfmdr1-2RK76T ${ }^{21}$ & & CCATCTTGATAAAAAACACTTCTT \\
\hline & MDR1-1246-pfmdr1-1FD1246Y21 & RT-PCR MDR B and sequencing & ATGACAAATTTTCAAGATTA \\
\hline & MDR2-1246-pfmdr1-1FD1246Y21 & & ACTAACACGTTTAACATCTT \\
\hline & MDR3-1246-pfmdr1-1FD1246Y21 & Sequencing & AATGTAAATGAATTTTCAAACC \\
\hline & MDR4-1246-pfmdr1-1FD1246Y21 & & CATCTTCTCTTCCAAATTTGATA \\
\hline \multirow[t]{4}{*}{ Cyt B } & CytB1-1F 22 & RT-PCR/sequencing & СTCTATTAATTTAGTTAAAGCACAC \\
\hline & CytB2-1 $R^{22}$ & & ACAGAATAATCTCTAGCACC \\
\hline & CytB3- $2 F^{22}$ & Sequencing & AGCAGTAATTTGGATATGTGGAGG \\
\hline & CytB4-2R 22 & & ATTTTTAATGCTGTATCATACCCT \\
\hline \multirow[t]{2}{*}{ K13 } & Pfal-k13-2-2PCR 20 & RT-PCR/sequencing & GCCAAGCTGCCATTCATTTG \\
\hline & Pfal-k13-3-2PCR ${ }^{20}$ & & GCCTTGTTGAAAGAAGCAGA \\
\hline
\end{tabular}

Hayward, CA, USA) in a final volume of $20 \mu \mathrm{l}$. The thermal cycle was performed in a Qiagen Rotor Gene Q 5 Plex HRM (QIAGEN ${ }^{\circledR}$, Hilden, Germany). The amplification conditions for the Pfmdr1 and Pfcytb genes were an initial cycle of denaturation of $10 \mathrm{~min}$ at $95{ }^{\circ} \mathrm{C}$, followed by 45 cycles of $15 \mathrm{~s}$ at $95^{\circ} \mathrm{C}, 15 \mathrm{~s}$ at $54{ }^{\circ} \mathrm{C}$ and $30 \mathrm{~s}$ at $68{ }^{\circ} \mathrm{C}$, ending with a melting step $\left(62{ }^{\circ} \mathrm{C}\right.$ to $\left.92{ }^{\circ} \mathrm{C}\right)$. In the case of the $P f K 13$ gene, the conditions were an initial denaturation cycle of $7 \mathrm{~min}$ at $94{ }^{\circ} \mathrm{C}$, followed by 40 cycles of $30 \mathrm{~s}$ at $94{ }^{\circ} \mathrm{C}, 1 \mathrm{~min}$ at $60{ }^{\circ} \mathrm{C}$ and $1 \mathrm{~min}$ at $72{ }^{\circ} \mathrm{C}$, ending with a melting step $\left(62{ }^{\circ} \mathrm{C}\right.$ to $\left.92^{\circ} \mathrm{C}\right)$.

Specificity of amplification was determined by post reaction analysis using the melting temperature (Tm) curve of the amplified fragments $\left(76.8^{\circ} \mathrm{C}\right.$ and $76.5^{\circ} \mathrm{C}$ for Pfmdr 1 fragment A and B respectively, $79.5^{\circ} \mathrm{C}$ for $P f c y t b$, and $82.0^{\circ} \mathrm{C}$ for $\left.P f K 13\right)$.

Amplicons were purified using Illustra DNA and Gel Band Purification Kit (General Electric Healthcare, England), then sequenced, with its specific primers (Table 1), using Big Dye Terminator v3.1 Kit in an ABI PRISM $^{\circledR}$ DNA Analyzer 3700. All amplified products were sequenced in both directions, twice. Blast tool from NCBI was used to confirm correct target amplification.
Multiple nucleotide sequence alignments and analysis were performed using BioEdit version 7.0.5.3 [23] using sequences from 3D7 strain as wild-type for comparison.

\section{Plasmodium falciparum genotyping}

Plasmodium falciparum genotyping was performed by characterizing two merozoite surface membrane genes ( $m s p-1$ and $m s p-2)$ by PCR described elsewhere [24, 25]. Multiplicity of infection (MOI) defined as the number of genetically distinct parasite strains co-infecting a single host, was determined as the largest number of different alleles present at one of the two loci studied.

\section{Kompetitive allele-specific PCR (KASP)}

Sequences flanking SNPs were submitted for KASP тм assay design to Biosearch Technologies (California, USA). KASP assay was carried out following the instructions of the manufacturer [6]. The reaction mix per reaction consists of $5.1 \mu \mathrm{l}$ of the KASP Master Mix, which include the two allele specific primers and one reverse primer (Table 2), and $0.138 \mu$ l of the Assay Mix, containing universal fluorescent probes, Taq polymerase and dNTPs in an optimized buffer solution.

Table 2 Primers and probes used for the SNPs characterization by the KASP method

\begin{tabular}{|c|c|c|}
\hline ID & Primer_AlleleX and Allele Y & Primer_Common \\
\hline Cyt b M1331 & $\begin{array}{l}\text { AATTACAGTTGCACCCCAATAACTC } \\
\text { GTAATTACAGTTGCACCCCAATAACTT }\end{array}$ & AACTGCTTTCGTTGGTTATGTCTTACCAT \\
\hline K13 C580Y & $\begin{array}{l}\text { ATACCCCTAGATCATCAGCTATGTG } \\
\text { AATACCCCTAGATCATCAGCTATGTA }\end{array}$ & CTCACCATTAGTTCCACCAATGACATAAA \\
\hline MDR N86Y & $\begin{array}{l}\text { GTGTTTGGTGTAATATTAAAGAACATGA } \\
\text { CTGTGTTTGGTGTAATATTAAAGAACATGT }\end{array}$ & GTACTAAACCTATAGATACTAATGATAATA \\
\hline
\end{tabular}


To five $\mu \mathrm{l}$ of this reaction mix, five $\mu \mathrm{l}$ of DNA from the sample to be analysed, are added. PCRs and fluorescent readings were performed in a Qiagen Rotor Gene Q 5 Plex HRM (QIAGEN ${ }^{\circledR}$, Hilden, Germany) following the recommended thermal cycling conditions (Table 3).

\section{Analysis of KASP genotyping data using cluster plots}

To analyse and interpret genotypic data, an Excel sheet is used, although it can also be done using the Thermo Fisher Cloud Genotyping application [26]. In a KASP general assay, a sample that is homozygous for the allele reported by the $\mathrm{X}$-signal oligonucleotide will only generate $\mathrm{X}$-signal fluorescence during the end-point genotyping reaction. This data point will be plotted close to the $\mathrm{X}$-axis, representing a high $\mathrm{X}$-signal and no Y-signal. A sample that is homozygous for the allele reported by the Y-signal oligonucleotide will only generate Y-signal fluorescence during the end-point genotyping reaction. This data point will be plotted close to the Y-axis, representing a high Y-signal and no X-signal. A heterozygous sample will contain both the allele reported by the X-signal oligonucleotide and the allele reported by the Y-signal oligonucleotide. This sample will generate half as much $\mathrm{X}$-signal fluorescence and half as much Y-signal fluorescence as the samples that are homozygous for these alleles. This data point will be plotted in the center of the plot, representing half X-signal and half Y-signal. In falciparum malaria, the situation is more complicated, since, in the blood phase infection, Plasmodium is haploid, but $P$. falciparum infections are usually multi-infection so different levels of "heterozygosis" can occur depending on the number of populations present in each infection (MOI). Thus, the points are scattered on the plot but always close to the corresponding axis if only one allele is present, while infections with both alleles will be located in the centre of the plot. Furthermore, to ensure the proper performance of the assay always is useful to include an end-point genotyping reaction without any

Table 3 Thermal cycle conditions for KASP genotyping reactions

\begin{tabular}{lllll}
\hline Step & Description & Temperature & Time & Cycles \\
\hline 1 & Activation & $94{ }^{\circ} \mathrm{C}$ & $15 \mathrm{~min}$ & 1 cycle \\
2 & Denaturation & $94^{\circ} \mathrm{C}$ & $20 \mathrm{~s}$ & 10 cycles \\
& Annealing/elongation & $61-55^{\circ} \mathrm{C}$ (drop & $60 \mathrm{~s}$ & \\
& & $0.6{ }^{\circ} \mathrm{C}$ per & & \\
& & $\mathrm{Cycle})$ & & \\
3 & Denaturation & $94^{\circ} \mathrm{C}$ & $20 \mathrm{~s}$ & 35 cycles \\
& $\begin{array}{c}\text { Annealing/elongation } \\
4\end{array}$ & $55^{\circ} \mathrm{C}$ & $60 \mathrm{~s}$ & \\
& Read stage (FAM ${ }^{\mathrm{TM}}, \mathrm{HEX}^{\mathrm{TM}}$, & $30^{\circ} \mathrm{C}$ & $60 \mathrm{~s}$ & \\
& ROX & & & \\
\hline
\end{tabular}

template DNA as a negative control (referred to as no template control or NTC) that should appear near zero in the cluster plot.

\section{Results}

Analysis for SNPs resistance genotyping showed that only 12 out of 112 samples show any mutations. In all cases this corresponded to amino acid position 86 , replacing asparagine with tyrosine (N86Y) of the Pfmdr1 gene. In the other two genes studied, Pfcytb and PfKelch13, no mutations were found. The $P$. falciparum strain from Malaysia was found to show the expected C580Y mutation in the PfKelch13 gene.

The KASP showed that none of the 24 negative samples were amplified, as did NTCs (no template control) included in each reaction. On the contrary, the KASP showed positive results in all the expected samples except one for the SNP of Pfmdr1, one more in the case of $P f c y t b$ SNP and 3 for PfK13 SNP. In all cases this lack of results was related to low parasitaemia; in the first two cases, where the samples were not amplified, presented a parasitaemia, quantified by real-time PCR, lower than 0.05 parasites $/ \mu \mathrm{l}$, being less than 1 parasites/ $\mu$ l for the PfK13. Despite these results, no statistical correlation has been observed between the level of parasitaemia and KASP values which are between -0.20 and -0.67 for wild genotypes and 0.20 for mutated genotypes.

The KASP result for Pfcytb M133I was that all of the amplified samples were wild type, as expected. Likewise, in the case of Pfk13 C580Y, all the samples showed the wild genotype, and only the control strain showed the mutated genotype. In the case of Pfmdr1 Y $86 \mathrm{~N}, 10$ samples gave a mutated genotype and two were characterized with a heterozygous genotype; the rest of the samples showed the wild genotype.

A factor that may also influence is the MOI, which ranges between 1 and 7 in the samples analysed, but no statistical correlation has been observed with the KASP values, obtaining values between -0.12 and 0.24 , except in one case that reaches 0.75 .

The reproducibility of the method was analysed by repeating two samples between four and six times in independent tests in the three SNPs, observing that the obtained values did not vary substantially as demonstrated by the low values of the standard deviation (Table 4).

The expected graphical KASP results should show three clusters, in addition to the negative controls, corresponding to wild type samples, to mutated samples and heterozygous samples (in our case, populations with both alleles). In the three SNPs studied the grouping of the samples according to the expected values are observed. For the Y86 N in the Pfmdr1 gene, the three clusters are present 
Table 4 Reproducibility of the KASP method

\begin{tabular}{|c|c|c|c|c|c|c|}
\hline Gen & Sample & Type & $\begin{array}{l}\text { Arithmetic mean } \\
\text { FAM filter }\end{array}$ & St. Deviation & $\begin{array}{l}\text { Arithmetic mean } \\
\text { HEX filter }\end{array}$ & St. Deviation \\
\hline \multirow[t]{2}{*}{ Pfmdr1 } & 222 & M & 0.08 & 0.00 & 0.59 & 0.04 \\
\hline & 223 & WT & 0.55 & 0.07 & 0.14 & 0.02 \\
\hline \multirow[t]{2}{*}{ PfK13 } & 222 & WT & 0.76 & 0.04 & 0.10 & 0.04 \\
\hline & 223 & WT & 0.76 & 0.07 & 0.07 & 0.008 \\
\hline \multirow[t]{2}{*}{ Pfcytb } & 222 & WT & 0.92 & 0.003 & 0.02 & 0.001 \\
\hline & 223 & WT & 0.48 & 0.003 & 0.08 & 0.0005 \\
\hline
\end{tabular}
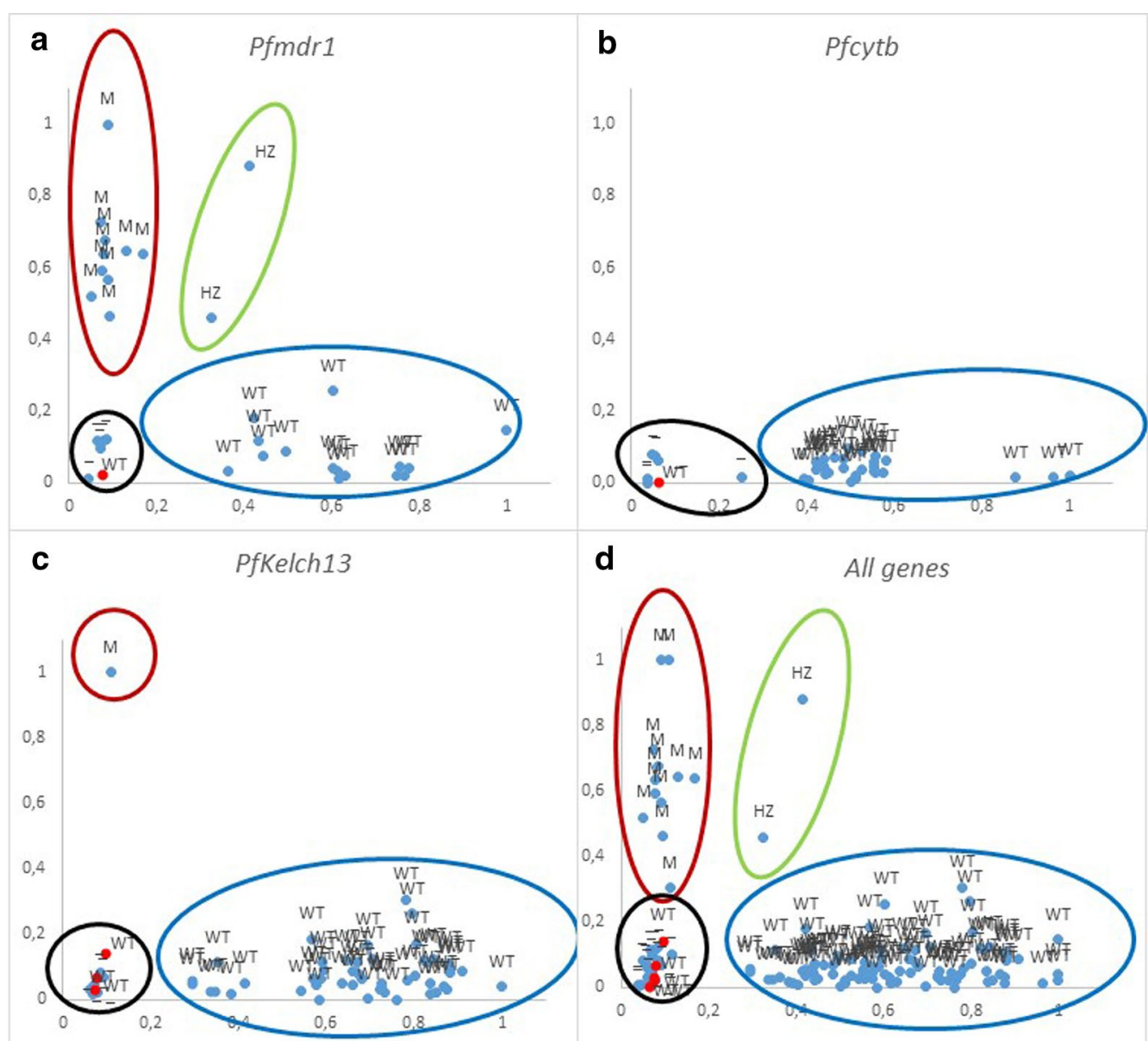

Fig. 2 Graphics showing genotypes of the Pfmdr1 (a), Pfcytb (b) and Pfk13 (c) genes, as well as a grouping of the data set (D). Red ovals correspond to WT genotype, blue to mutated genotype, yellow to heterozygous genotypes and green negative controls samples and non-template controls (NTC). Red dots correspond to positives samples that were not detected due to their low parasitaemia. WT wild type, HZ heterozygous type, $M$ mutated type

(Fig. 2a); in the case of the C580Y in the PfK13, the cluster of the wild type genotype and that of the mutated strain are observed (Fig. 2c) and in the case of M133I in Pfcytb only wild samples are observed (Fig. 2b). By grouping all the SNPs in a single graph, the same result is obtained, with the four clusters well defined (Fig. 2d). 


\section{Discussion}

The development and utilization of genetic markers play a pivotal role in the study of malaria pathology in general and in resistance analysis in particular. Among molecular markers, SNPs have become the most promising due to their wide distribution within genomes and suitability for high-throughput automated genotyping [27]. Different methodologies, such as TaqMan, KASP, and rhAmp, have been proposed for the analysis of SNPs using highresolution automated systems [26]. The Kompetitive Allele Specific PCR genotyping system $\left(\mathrm{KASP}^{\mathrm{TM}}\right.$ ) is a homogeneous, fluorescent, endpoint genotyping technology whose use is expanding in plant genotyping [26, 27]. In malaria, especially in the study of $P$. falciparum, the design of a set of core SNPs array based on this technique could be very interesting for the study of resistance and other SNPs associated with pathology [28]. Firstly, it is necessary to validate this methodology for Plasmodium due to the special characteristics of this parasite and the multiple infections it produces.

The system is designed in principle to characterize the presence of bi-alleles in samples of diploid organisms, although its efficacy has also been seen in hexaploid organisms such as wheat [26]. Plasmodium in humans is haploid, the only phases where this organism is diploid occurs in the anopheline vector, but the infection, in general, is produced by several genetically distinct parasite strains co-infecting a single host (MOI), therefore, the genotype of a sample for a given gene can cover all allelic variants, being able to present the homozygote of both types or the heterozygote.

The KASP values obtained could be influenced either by the parasitaemia or by the MOI of the samples. Parasitaemia, whose detection limits range from 1 parasites/ $\mu l$ in the case of the analysis of $P f k 13$ to 0.05 parasites/ $\mu \mathrm{l}$ in $P f m d r 1$ and $P f c y t b$, does not influence the KASP values, as demonstrated by the low statistical correlation values (-0.67 to 0.20$)$. Similarly, no correlation was found between the MOI and the KASP values of the sample $(-0.12$ to 0.75$)$. In both cases, the values obtained are very far from the expected values around \pm 1 in the event of a correlation.

In the three SNPs studied, the values obtained correspond to the expected, except in two samples in the Y $86 \mathrm{~N}$ mutation in the Pfmdr1 gene, which according to KASP we would have both alleles in the sample. This type of case cannot be solved by direct sequencing of the amplified product since in this case only the majority form is detected or in any case, an indeterminacy would occur in the involved nucleotide. The cloning and sequencing of multiple clones or pyrosequencing could resolve this heterozygosis but at a higher cost and with more delay than the KASP. The reproducibility of the technique is very good, showing no oscillations between repetitions in any of the three SNPs analysed (Table 4).

The KASP assays developed in our study were efficient and versatile for the determination of the Plasmodium genotypes related to resistance, not being influenced by the parasitaemia of the infection nor by the number of populations involved in it (MOI), and showing high reproducibility.

In conclusion, the method is simple, fast, reproducible and scalable, being able to core KASP arrays developed including numerous SNPs, and, on the other hand, the cost in personnel, material and equipment is lower than with other methodologies.

\section{Abbreviations}

Amino acids C: Cysteine; Y: Tyrosine; N: Asparagine; M: Methionine; I: Isoleucine; KASP: Kompetitive allele-specific PCR; MOI: Multiplicity of infection; Pfmdr1: P. falciparum multi drug resistance gene 1; Pfcytb: P. falciparum gene cytochrome b gene; PfK13: P. falciparum Kelch13 gene; SNP: Single nucleotide polymorphism.

\section{Acknowledgements}

Special thanks to the team of collaborators belonging to the Spanish submicroscopic malaria study group.

\section{Authors' contributions}

JMR, SH and APA conceptualized the study. JMR, AAF, MJB, AMR, NAY designed the experiments. JMR provided training and supervision for the procedures. IFV, APA recruited patients and maintained databases. AAF, MJB, AMR, NAY, MLS performed the experiments. All authors contributed to the writing of the final version of the manuscript. All authors read and approved the final manuscript.

\section{Funding}

This work was funded by projects PI17/01791 and PI17CIII/00035 from the Instituto de Salud Carlos III (Ministry of Science and Innovation) and cofounded by the European Regional Development Fund. AMR is financed with an ISCIII- RIO HORTEGA contract (AESI RRHH-2017) from the Instituto de Salud Carlos III (Ministry of Science and Innovation). MJB is financed with a project associated contract from the Instituto de Salud Carlos III (Ministry of Science and Innovation)

\section{Availability of data and materials}

All data analyzed during the study are included in this published article. The full datasets of $P$. falciparum genotyping generated during the current study are not publicly available due to its future publication but are available from the corresponding author on reasonable request.

\section{Ethics approval and consent to participate}

This work is part of a prospective, observational, multicenter study, approved by the Medical and Health Research Ethics Committee (CEIC) of the Hospital Universitario 12 de Octubre (CEIm: 18/021), Madrid, Spain.

\section{Consent for publication}

Not applicable.

\section{Competing interests}

The authors declare that they have no competing interests.

\section{Author details}

${ }^{1}$ Malaria \& Parasitic Emerging Diseases Laboratory, National Microbiology Center, Instituto de Salud Carlos III, Madrid, Spain. ${ }^{2}$ Department of Clinical Microbiology, Hospital Universitario, 12 de Octubre, Madrid, Spain. 

${ }^{3}$ Parasitology Unit, Infectious Disease Research Centre, Institute for Medical
Research, National Institute of Health, Setia Alam, Selangor, Malaysia.

Received: 15 July 2020 Accepted: 11 December 2020

Published online: 06 January 2021

\section{References}

1. WHO. World malaria report 2019. Geneva: World Health Organization; 2019.

2. Otienoburu S, Suay I, Garcia S, Thomas N, Srisutham S, Björkman A, et al. An online mapping database of molecular markers of drug resistance in Plasmodium falciparum: the ACT Partner Drug Molecular Surveyor. Malar J. 2019;18:12.

3. Cowell A, Winzeler E. The genomic architecture of antimalarial drug resistance. Brief Funct Genomics. 2019;18:314-28.

4. Hartl D. The origin of malaria: mixed messages from genetic diversity. Nat Rev Microbiol. 2004;2:15-22.

5. WHO. Artemisinin resistance and artemisinin-based combination therapy efficacy. Geneva: World Health Organization; 2018.

6. He C, Holme J, Anthony J. SNP genotyping: the KASP assay. Methods Mol Biol. 2014;1 145:75-86.

7. Leelawong M, Adams N, Gabella W, Wright D, Haselton F. Detection of single-nucleotide polymorphism markers of antimalarial drug resistance directly from whole blood. J Mol Diagn. 2019;21:623-31.

8. Semagn K, Babu R, Hearne S, Olsen M. Single nucleotide polymorphism genotyping using Kompetitive Allele Specific PCR (KASP): overview of the technology and its application in crop improvement. Mol Breeding 2013;33:1-14.

9. Suo W, Shi X, Xu S, Li X, Lin Y. Towards low cost, multiplex clinical genotyping: 4-fluorescent Kompetitive Allele-Specific PCR and its application on pharmacogenetics. PLoS ONE. 2020;15:e0230445.

10. Ciosi M, Maxwell A, Cumming S, Moss D, Alshammari A, Flower M, et al. A genetic association study of glutamine-encoding DNA sequence structures, somatic CAG expansion, and DNA repair gene variants, with Huntington Disease clinical outcomes. EBioMedicine. 2019;48:568-80.

11. Dombrowski J, Souza R, Curry J, Hinton L, Silva N, Grignard L, et al. G6PD deficiency alleles in a malaria-endemic region in the Western Brazilian Amazon. Malar J. 2017;16:253.

12. Zaw M, Lin Z, Emran N. Importance of kelch 13 C580Y mutation in the studies of artemisinin resistance in Plasmodium falciparum in Greater Mekong Subregion. J Microbiol Immunol Infect. 2020;53:676-81.

13. Lekana-Douki J, Boutamba S, Zatra R, Edou S, Ekomy H, Bisvigou U, et al. Increased prevalence of the Plasmodium falciparum Pfmdr1 $86 \mathrm{~N}$ genotype among field isolates from Franceville, Gabon after replacement of chloroquine by artemether-lumefantrine and artesunate-mefloquine. Infect Genet Evol. 2011;11:512-7.

14. Li J, Chen J, Xie D, Monte-Nguba S, Eyi J, Matesa R, et al. High prevalence of pfmdr1 N86Y and Y184F mutations in Plasmodium falciparum isolates from Bioko island. Equatorial Guinea. Pathog Glob Health. 2014;108:339-43.

15. Sisowath C, Strömberg J, Mårtensson A, Msellem M, Obondo C, Björkman A, et al. In Vivo Selection of Plasmodium falciparum pfmdr186N
Coding Alleles by Artemether-Lumefantrine (Coartem). J Infect Dis. 2005;191:1014-7.

16. Schwöbel B, Alifrangis M, Salanti A, Jelinek T. Different mutation patterns of atovaquone resistance to Plasmodium falciparum in vitro and in vivo: rapid detection of codon 268 polymorphisms in the cytochrome b as potential in vivo resistance marker. Malar J. 2003;2:5.

17. Blake L, Johnson M, Siegel S, McQueen A, Iyamu I, Shaikh A, et al. Menoctone resistance in malaria parasites is conferred by M133I mutations in Cytochrome $b$ that are transmissible through mosquitoes. Antimicrob Agents Chemother. 2017;61:e00689-717.

18. Miguel-Oteo M, Jiram A, Ta-Tang T, Lanza M, Hisam S, Rubio J. Nested multiplex PCR for identification and detection of human Plasmodium species including Plasmodium knowlesi. Asian Pac J Trop Med. 2017;10:299-304.

19. Rubio JM, Post RJ, Docters van Leeuwen WM, Henry MC, Lindergard G, Hommel M. Human malaria diagnosis by seminested mutiplex PCR: Field trials, human blood and dried blood-spot samples. Trans R Soc Trop Med Hyg. 2002;96:199-204.

20. Ariey F, Witkowski B, Amaratunga C, Beghain J, Langlois A, Khim N, et al. A molecular marker of artemisinin-resistant Plasmodium falciparum malaria. Nature. 2013;505:50-5.

21. Happi T, Thomas S, Gbotosho G, Falade C, Akinboye D, Gerena L, et al. Point mutations in the pfcrt and pfmdr-1 genes of Plasmodium falciparum and clinical response to chloroquine, among malaria patients from Nigeria. Ann Trop Med Parasitol. 2003;97:439-51.

22. Korsinczky M, Chen N, Kotecka B, Saul A, Rieckmann K, Cheng Q. Mutations in Plasmodium falciparum cytochrome $b$ that are associated with atovaquone resistance are located at a putative drug-binding site. Antimicrob Agents Chemother. 2000;44:2100-8.

23. Hall TA. BioEdit: a user-friendly biological sequence alignment editor and analysis program for Windows 95/98/NT. Nucl Acids Symp Ser. 1999;41:95-8

24. Robert F, Ntoumi F, Angel G, Candito D, Rogier C, Fandeur T, et al. Extensive genetic diversity of Plasmodium falciparum isolates collected from patients with severe malaria in Dakar, Senegal. Trans R Soc Trop Med Hyg. 1996;90:704-11.

25. Snounou G, Zhu X, Siripoon N, Jarra W, Thaithong S, Brown K, et al. Biased distribution of $\mathrm{msp} 1$ and $\mathrm{msp} 2$ allelic variants in Plasmodium falciparum populations in Thailand. Trans R Soc Trop Med Hyg. 1999;93:369-74.

26. Ayalew H, Tsang P, Chu C, Wang J, Liu S, Chen C, et al. Comparison of TaqMan, KASP and rhAmp SNP genotyping platforms in hexaploid wheat. PLOS ONE. 2019;14:e0217222.

27. Yang G, Chen S, Chen L, Sun K, Huang C, Zhou D, et al. Development of a core SNP arrays based on the KASP method for molecular breeding of rice. Rice (NY). 2019;12:21.

28. Milner D, Vareta J, Valim C, Montgomery J, Daniels R, Volkman S, et al. Human cerebral malaria and Plasmodium falciparum genotypes in Malawi. Malar J. 2012;11:35.

\section{Publisher's Note}

Springer Nature remains neutral with regard to jurisdictional claims in published maps and institutional affiliations.

Ready to submit your research? Choose BMC and benefit from:

- fast, convenient online submission

- thorough peer review by experienced researchers in your field

- rapid publication on acceptance

- support for research data, including large and complex data types

- gold Open Access which fosters wider collaboration and increased citations

- maximum visibility for your research: over $100 \mathrm{M}$ website views per year

At BMC, research is always in progress.

Learn more biomedcentral.com/submissions 